\title{
Challenges and Issues of Medical and Nursing Education: An Outcome qualitative Research at various Medical/Nursing Institutes of Pakistan
}

\author{
Article by Sumera noshin \\ Education, Texila American University, Pakistan \\ Email: sumera.noshin@gmail.com
}

\begin{abstract}
Objectives: To evaluate the consequences of individualized education and systematic social contract education through exploring education systems of various training institutes. Materials \& Methods: Qualitative design was applied and data were collected through using interview guide/topic guide. Data was collected on emails, telephone, and face to face interviews, till saturation. Data was collected in the months of January and February 2017 with different types of participants. Participants were selected using purposive and networking sampling from various medical/nursing colleges. Finally, 4 patients, 4 students 4 faculty members 6 academic key informants, were selected for interview. Results: After analyzing and data interpretation, the challenges and issues are categorized in four main themes, including 1. Deficient Multidisciplinary /multi-setting teaching methodology, 2. Curriculum paradigm shift, 3. Curriculum misalignment and 4. Need for Professionalism. Each of these main themes comprises several subthemes and accordingly each subtheme encompasses several issues. Each issue is presented in form of verbatim. Recommendations: Curriculum revisions and retreat can help in facing the challenges and fixing up the issues. Research and program evaluation is mandatory for the curriculum paradigm shift.
\end{abstract}

Keywords: Multidisciplinary teaching, Multi-setting teaching methodology, Curriculum paradigm shift, Curriculum alignment, Curriculum misalignment.

\section{Introduction}

Doctors and nurses as healthcare providers are critically observed by the society as highly respectable members of the society. They not only deal with the lives of the patients rather with their emotions, feeling and thoughts with an extreme of accountability and responsibility. Medical/nursing profession is very sensitive and one error, no matter how minor or insignificant for the professional, can stamp badly to the minds of patient, family and community. To avoid serious repercussion, it is imperative that medical/nursing graduates should have the requisite sound professional knowledge, skills, and most importantly attitude to deal head on with the challenges that real life brings to them. In recent past the paradigm shift of professional educational system have brought certainly a rise in professional education but unfortunately a fall in professionalism and decline of ethical human care.

Fundamentally education is one of the most important issues that could affect nurses and doctors to work in an ethical and professional manner. Regarding to importance of the issue, the present research aimed at exploring challenges in medical/nursing education that makes them away from social contract. This issue is very important and the results of this research could help policy makers and educational planners for addressing the said issue (Earle, Scribani, Scott, May, \& Jenkins, 2015).

\section{Materials and methods}

Qualitative design was applied for the purpose of the study and data were collected through using interview guide/topic guide (Refer Appendix "A"). This interview guide was used to collect data on emails, on telephone, and face to face interviews. Prior to starting qualitative study, reviewing the literature and a pilot study was done and accordingly interview guide for interviews was extracted for 
DOI: $10.21522 / \mathrm{TIJAR} .2014 .04 .02 . A r t 015$

ISSN: $2520-3088$

interviews. Topic guide mainly focused on challenges of medical and nursing education in various teaching hospitals and institutes of Pakistan. Questions of topic guide were about challenges/issues and planning to meet those challenges in future. Some modifications in interview guide were made after pilot interviews. The outcomes from pilot study were Professional communication gap, Theory practice gap, and less interaction with patient, family, community and society at large.

Based on pilot topic guide and its modifications, semi-structured interviews were conducted in the months of January and February 2017 with different types of participants.

Participants were divided in main categories including, patients $(\mathrm{P})$, medical/nursing students (MS, NS), faculty members (F), academic key informants (AKI), executive key informant (EQI) from medical and nursing colleges and institutes. Participants were selected using purposive and networking sampling. Army and civil areas are tried to cover and sample was selected from all over the country at micro and macro level of the Pakistan's health education system. Data was taken from Combined Military Hospital Multan Institute of Medical Sciences, Shifa Tameer-e- Millat University Islamabad. National University of Medical Sciences Rawalpindi, Shalimar College of Nursing Lahore, and Syeda Waheed College of Nursing Lahore.

Interviews were performed until reaching to data saturation. Finally, 4 patients, 4 students 4 faculty members 6 academic key informants, were selected for interview. No executive key informants responded either on email or text. Although, most of participants had studied medicine and nursing and were well informed about their education system and thus the results would be reliable.

Face to face and telephonic interview time varied from 20 minutes to 35 minutes. Most of the participant did not allow recording of conversation, only 2 were recorded and transcribed verbatim and in one case interviewer noted during interview. Data were analyzed using thematic analysis approach. In this way, texts were coded and issues and subthemes were extracted. Several ethical issues were considered in interviews with participants. All participants were consented to participate in the study and free to express their opinions about the subject. Interviewees were ensured the confidentiality of emails, recorded and noted interviews and their names and positions. As well, the study protocol complies with the ethical guidelines of the 1975 Declaration of Helsinki and approved by the higher authorities of GHQ (Refer Authority letter number in consent form and interview guide).

\section{Results}

After analyzing and data interpretation, four main themes were found, including professionalism, multidisciplinary /multi-setting teaching methodology, curriculum paradigm shift, and curriculum alignment. Each of these main themes encompasses several subthemes and accordingly each subtheme encompasses several issues. The thematic framework of the findings is presented in Table 1. According to table 1 challenges and issues in medical/nursing education are as follows:

Table 1. Thematic framework of challenges and issues in medical/nursing education (verbatim are written after the thematic framework)

\begin{tabular}{|l|l|l|}
\hline Main Themes (MT) & Sub Themes (ST) & Issues (I) \\
\hline MT.1.Professionalism & ST. 1.Communication & $\begin{array}{l}\text { 1. Lacks in therapeutic } \\
\text { communication } \\
\text { 2. Non-touch techniques of } \\
\text { patient assessment }\end{array}$ \\
\hline & $\begin{array}{l}\text { ST. 2.Ethics : } \\
\text { Violating ethical } \\
\text { principles }\end{array}$ & $\begin{array}{l}\text { 1. Unjustified care to } \\
\text { officers vs soldiers, paid vs } \\
\text { unpaid } \\
\text { 2. Breach of } \\
\text { confidentiality and privacy } \\
\text { 3. Not finding a human in }\end{array}$ \\
\hline
\end{tabular}




\begin{tabular}{|c|c|c|}
\hline & & a patient \\
\hline & ST. 3.Esthetics & $\begin{array}{l}\text { 1. Robotic styled care } \\
\text { providers }\end{array}$ \\
\hline & ST. 4.Self-perception & 1. Self-importance \\
\hline \multirow[t]{2}{*}{$\begin{array}{l}\text { MT.2.Multi-disciplinary, } \\
\text { Multi-setting teaching } \\
\text { methodology }\end{array}$} & $\begin{array}{l}\text { ST. 5.Nurse-Doctor } \\
\text { mentorship and } \\
\text { preceptorship }\end{array}$ & $\begin{array}{l}\text { 1. Separate teaching and } \\
\text { learning entities of doctors } \\
\text { and nurses } \\
\text { 2. No harmony and } \\
\text { therapeutic inter and intra } \\
\text { personal elation ships }\end{array}$ \\
\hline & $\begin{array}{l}\text { ST. 6.Education } \\
\text { setting and Approach }\end{array}$ & $\begin{array}{l}\text { 1. All teaching tenures } \\
\text { remains stagnant } \\
\text { 2. Less exposure in } \\
\text { community settings, except } \\
\text { OPDs }\end{array}$ \\
\hline \multirow[t]{2}{*}{$\begin{array}{l}\text { MT.3.Curriculum paradigm } \\
\text { shift }\end{array}$} & $\begin{array}{l}\text { ST. 7.Transformation } \\
\text { of traditional teaching } \\
\text { system }\end{array}$ & $\begin{array}{l}\text { 1. Modular system of } \\
\text { education is newly adopted } \\
\text { and started without training } \\
\text { of faculty }\end{array}$ \\
\hline & $\begin{array}{l}\text { ST. 8. Eclectic } \\
\text { curriculum vs model } \\
\text { based curriculum }\end{array}$ & $\begin{array}{l}\text { 1. Few institutes are still } \\
\text { on eclectic approach } \\
\text { 2. Few adopted one model } \\
\text { for entire program, rather } \\
\text { using variety of subject } \\
\text { wise models }\end{array}$ \\
\hline \multirow[t]{2}{*}{ MT.4.Curriculum alignment } & $\begin{array}{l}\text { ST. 9.Undefined } \\
\text { Philosophies }\end{array}$ & $\begin{array}{l}\text { 1. Educational } \\
\text { philosophies are not } \\
\text { reflecting in curriculum }\end{array}$ \\
\hline & $\begin{array}{l}\text { ST. 10.Misalignment } \\
\text { with supporting } \\
\text { subjects }\end{array}$ & $\begin{array}{l}\text { 1. Lack of social contract } \\
\text { due individualized mode of } \\
\text { education } \\
\text { 2. Missing of social } \\
\text { sciences subjects }\end{array}$ \\
\hline
\end{tabular}

\section{Professionalism}

\section{Lacks in therapeutic communication}

A participant's (NS) verbatim I don't feel confident in discussing with doctors about care plan of my ward patients, I want to match nursing diagnoses with medical diagnoses, I want to do health assessment with doctor or want to share my findings of assessment documentation, but I don't have document to write nurses notes, and as subordinate or separate entity from doctors I kept silent while conducting daily ward round.

\section{Non-touch techniques of patient assessment}

A participant's (P) verbatim: Sister mareezon se ziada files main masroof rehti hain, Doctor Sahib door hi say keh daitay hain mareez ki saans (breathing) theek nahi lag rahi machine (Nebulizer) lagado.

\section{Unjustified care to officers vs soldiers, paid vs unpaid}

A participant's $(\mathrm{P})$ verbatim: .......ajkal kay doctors and sisters bhi politician ho gay hain. Jahan se faida ho whai pe care bhi di jati hy........ 
DOI: $10.21522 / \mathrm{TIJAR} .2014 .04 .02 . A r t 015$

ISSN: $2520-3088$

\section{Breach of confidentiality and privacy}

A participant's (MS) verbatim: I don't feel good to discuss about personals of a patient during ward round and in a team of doctors. Ward sisters also discuss everything on the counter and all patients listen about every patient.......

\section{Not finding a human in a patient}

A participant's (P) verbatim: Hospital main aa $k$ lagta hy $k$ hum insaan nahi hain. Hamain aik qitaar main laga diya jata hy medicines and treat ment $k$ liyay

\section{Robotic styled care providers}

A participant's (P) verbatim: Sister main aur robot min koi faraq nhi lagta, muskurana tou door ki baat hay, .....tassali (counselling) ka aik lafz nhi boltin........

\section{Self-importance}

A participant's (P) verbatim: Doctor sahib tou bahot parhy likhay aur masroof insaan hain, kehtay hain kay hmari baat kay liyay unkay pass time nahi hay........unko aur bhi bahot kaam hotay hain.

\section{Multi-disciplinary, Multi-setting teaching methodology}

\section{Separate teaching and learning entities of doctors and nurses}

A participant's (MS) verbatim: I don't know the types of taught subjects and depth of knowledge nurses have, .......am not aware of nurses jobs and responsibilities, I think they are care takes of ward and equipment.

\section{No harmony and therapeutic inter and intra personal relationships}

A participant's (NS) verbatim: Hum logon ne koi subject ikathay (together) nahi parha. Koi case study ya case management ikathay plan ya present nahi ki........

\section{All teaching tenures remains stagnant}

A participant's (NS) verbatim: Har subject ki class room teaching similar hay...... I think har subject ki teaching methodology and setting change honi chahiyay

\section{Less exposure in community settings, except OPDs}

A participant's $(\mathrm{P})$ verbatim:

A participant's (MS)Verbatim:

We are educated in an ideal environment ...we weren't prepared for an overcrowded OPD and general ward settings.

Another participant's (NS) Verbatim:

Ward kay patients ka kaam tou kafi kia hay lekin mera community work ka koi experience nahi hy

\section{Curriculum paradigm shift}

1. Modular system of education is newly adopted and started without training of faculty

A participant's (AKI) Verbatim: Modular system is started now a dys, but no prior traing is given to the trainers.........

2. Few institutes are still on eclectic approach

A participant's (AKI) Verbatim: No model based curriculum is being followed in our universities, even though we are planning to do so......

3. Few adopted one model for entire program, rather using variety of subject wise models

A participant's (AKI) Verbatim: ....we are using SPICES model for the curriculum of medicine...... 


\section{Curriculum alignment}

1. Educational philosophies are not reflecting in curriculum

A participant's (AKI-1) Verbatim: We are using social constructivisim as philosophy .....

A participant's (AKI-2) Verbatim: We are using philosophy of constructivisim .....

A participant's (AKI-3\&4) Verbatim: philosophy is undefined ....

2. Lack of social contract due individualized mode of education

There are some challenges regarding to curriculum of medical/nursing education; i.e., some courses are needed for preparing students for working in social contract. In this study we found that focusing on skills needed for general public practice, health related courses, management and leadership, communication, and medical ethics could make a student ready to an accept practicing in all types of settings.

A participant's (MS) Verbatim:

After graduation at the first day of practice in general ward. I had a patient and I wanted to fill and sign the referral sheet for the patient. I was not knowing how to handle the sheet and crowd of attendants around the patient...the patient found this and this resulted in bad reputation of me as newly graduate... They think that I don't have enough skill of treating......

Another point is that newly graduates in general OPD and wards settings where work is more on health issues instead of treatment and cure. They are the head of health system and they need to have perception about health subjects such as epidemiology, social determinants of health, health houses and their functions, etc. Nevertheless, as newly graduate stated, their education is different from what is needed in actual settings. They learn mainly about treatment of complicated cases in specialized hospitals.

A participant's (MS) Verbatim:

...we need to learn humble health and social issues that we need them more in actual practical settings...instead of many complicated health issues....

3. Missing of social sciences subject

A participant's (MS) Verbatim: The supporting subjects should start in year one of medicine..........

A participant's (NS) Verbatim: I have knowledge of sociology and psychology, where I know human relationships and interaction with diverse type of patients.....

\section{Discussion}

Nurses and doctors are the key healthcare provider in health care settings. Education is a factor that could affect the performance and conduct of these health care providers. Accordingly this qualitative outcome research was done to find educational challenges that limit health care providers to work in professional, ethical and subtle human care. According to the results four main challenges were, including professionalism, multidisciplinary /multi-setting teaching methodology, curriculum paradigm shift, and curriculum alignment (Ganle, Parker, Fitzpatrick, \& Otupiri, 2014).

\section{Professionalism}

A challenge was related to students' perception about their future working condition. Most of students look for specialized courses in medicine and they would not stay general physicians. They do not consider general practice after graduation in many cases. In fact Students' perception about their personal career development is a factor that affects their behavior, conduct and communication with the patients. Personal and professional expectations also proved as a factor affecting on practice. On the other hand students are not exposed to actual crowded and busy clinical settings. Accordingly it seems necessary that some modification in education is needed to guide students' perception toward general practice in a professional way (McLean, Guthrie , Mercer, \& Watt, 2015), (Unwin, \& Peters, 2016

\section{Multidisciplinary /multi-setting teaching methodology}

Another challenges that was found in this research were challenges related to education setting and approach. Instructors and education location as well as education approach could have a significant 
DOI: $10.21522 / \mathrm{TIJAR} .2014 .04 .02 . A r t 015$

ISSN: $2520-3088$

impact on graduates (Kulig, Kilpatrick, Moffitt, Zimmer 2015), (Rahman, Maharaj, Yates, Beeley, Moore, Rose, 2015).

In Pakistan, medical/Nursing education is hospital oriented. Most of practical courses are presented in hospitals and students are not getting familiar with community settings and health issues. This approach could have a significant effect on medical/nursing students' perception about their future working condition.

Instructors are one of the important factors in education that could guide student's ideas and thoughts. Instructors who experienced working in all types of clinical settings and try to motivate their students for all types of practice are key factors. Students patterned form their instructors and if they stress on selfsacrifices, the spirit of working for deprived people, and medical ethics, students will be affected.

Education setting and approach could be as important as curriculum. It refers to factors that education is delivered via them including education approach, place of education, and instructors.

\section{Curriculum paradigm shift}

Medical curriculum has been recently transformed from traditional to modular approach and on SPICES, but still in infancy period as faculty is not yet prior or along with prepared for such a big change. Nursing curriculum is as semester system and curriculum is being in revision phase.

\section{Curriculum alignment}

Curriculum of medical education in Pakistan is a factor that does not properly make graduates ready for handling social issues. Authors consider curriculum as a factor that build an image for future working. The medical curriculum in Pakistan is individual-oriented; whereas, community or social-oriented education increases intention of working. Though, the students are not getting familiar with skills needed for social practice (Qing, Hu, Chen, Peng, Li \& Wei 2015).

A robust curriculum, becoming a diseased curriculum which is called "Curriculomegaly" although less important than the quality of the teachers, is a factor that effects medical education imparted to young undergraduates. Curriculum needs constant revision in the light of changing social circumstances. The unparalleled pace of progress in medical sciences has translated into "information overload', causing an ever increasing amount of material taught to the students, stifling their education by the accretion of facts and technological information. Uncontrolled transfer of information has led to repetition and disjointed teaching and lessening the attention to be paid on real, actual societal issues (Kawamoto, Uemoto, Ninomiya, Hasegawa, Ohtsuka, \& Kusunoki 2015).

\section{Recommendations}

There is strong needing felt to revisit the methods by which our students are converted from raw recruits into medical/nursing graduates. In simple terms, professional education needs to be constantly updated in response to our social needs and requirements of the professional practice. A first year student of medicine or nursing should start interacting with patient as to evolve into a medical practitioner. This is to best utilize their intellectual acumen, interests, and foster social activities. Two factors that are in the control of the institutes and colleges that is the quality of teaching faculty and the curriculum. Staff development programs should be on cont focusing on improving teaching skills.

\section{References}

[1].Earle-Richardson G, Scribani M, Scott E, May J, Jenkins P. A comparison of health, health behavior, and access between farm and nonfarm populations in rural New York state. J Rural Health 2015; 31 (2):157-164.

[2].Ganle JK, Parker M, Fitzpatrick R, Otupiri E. A qualitative study of health system barriers to accessibility and utilization of maternal and newborn healthcare services in Ghana after userfee abolition. BMC Pregnancy Childbirth 2014; 14: 425.

[3].Kawamoto R, Uemoto A, Ninomiya D, Hasegawa Y, Ohtsuka N, Kusunoki T, et al. Characteristics of Japanese medical students associated with their intention for rural practice. Rural Remote Health 2015; 15(2):3112. 
[4].Kulig JC, Kilpatrick K, Moffitt P, Zimmer L. Recruitment and retention in rural nursing: it's still an issue! Nurs Leadersh (Tor Ont) 2015; 28(2):40-50.

[5].McLean G, Guthrie B, Mercer SW, Watt GC. General practice funding underpins the persistence of the inverse care law: cross-sectional study in Scotland. Br J Gen Pract 2015; 65(641):e799-e805.

[6].Qing Y, Hu G, Chen Q, Peng H, Li K, Wei J, et al. Factors that influence the choice to work in rural township health centers among 4,669 clinical medical students from five medical universities in Guangxi, China. J Educ Eval Health Prof 2015; 12: 40.

[7].Rahman FR, Maharaj V, Yates R, Beeley C, Moore I, Rose A, et al. Addressing the inverse care law: the role of community paediatric services. Perspect Public Health 2014; 134(2):85-92.

[8].Unwin J, Peters D. Gatekeepers and the Gateway--a mixed-methods inquiry into practitioners' referral behaviour to the Gateway Clinic. Acupunct Med 2009; 27(1):21-25. 